Article

\title{
An Econophysics Study of the S\&P Global Clean Energy Index
}

\author{
Paulo Ferreira 1,2,3,*(D) and Luís Carlos Loures ${ }^{1,2}$ (D) \\ 1 VALORIZA-Research Center for Endogenous Resource Valorization, 7300-555 Portalegre, Portugal; \\ lcloures@ipportalegre.pt \\ 2 Instituto Politécnico de Portalegre, 7300-110 Portalegre, Portugal \\ 3 CEFAGE-UE, IIFA, Universidade de Évora, 7000 Évora, Portugal \\ * Correspondence: pferreira@ipportalegre.pt; Tel.: +351-268-628-528
}

Received: 5 November 2019; Accepted: 14 January 2020; Published: 16 January 2020

\begin{abstract}
The study of how financial markets behave continues to be interesting. The existence of more and more data and the development of statistical techniques are some reasons for the increase in research in finance. However, the difficulty in understanding some markets' behavior is a continuous challenge. In this context, a new research area called Econophysics has emerged, which is constantly increasing in size. We propose in this work to use methodologies related to Econophysics to analyze one stock index composed of firms producing clean energy (S\&P Global Clean Energy Index) and compare it with the New York Stock Exchange (NYSE) as a stock market benchmark and with the price of crude oil. In a context where environmental issues are on the agenda, this is an important area of research, because it could help investors to make their decisions. Our results show that the clean energy index seems to have higher time serial dependence than the others, and is less exposed to oil price than the NYSE.
\end{abstract}

Keywords: correlation coefficient; detrended cross-correlation analysis; detrended fluctuation analysis; econophysics; efficiency

\section{Introduction}

The study of how financial markets behave is not new in the financial literature. At least since the seminal work of [1], researchers have tried to explain how these markets evolve. Later in that century, [2,3] revolutionized the study of finance by identifying the efficient market hypothesis (EMH), which in its weak form (i.e., when agents consider the information set of historical prices) states that asset prices are expected to follow a random walk, meaning return rates should not suffer from any kind of serial dependence (hereafter, we refer only to dependence to identify this feature). Since the work of Fama, researchers have tried to confirm the existence or not of market efficiency. The use of different methodologies, spatial and time samples and the increasing amount of data mean there is a vast amount of research.

The huge amount of data drew the attention of a particular audience of researchers. Statistical physicists started to manage and study financial data, creating an interdisciplinary research area called Econophysics (see [4-7] for recent reviews). The use of detrended fluctuation analysis (DFA) and detrended cross-correlation analysis (DCCA) come under this research area and will be used here. DFA is used to analyze the dependence pattern of a given time series, and is usually identified as a way to study the efficiency level of financial markets.

While DFA analyzes the behavior of individual time series, DCCA (and its correlation coefficient) is applied to analyze long-range correlations between different time series. The objective is to identify the connectivity in markets, studying how they relate to each other. 
In this work, we propose to analyze the S\&P Clean Energy Index, an index composed of companies doing business related to clean energy. Particularly, we will use DFA to analyze the dependence pattern of the time series of that index, comparing it with the New York Stock Exchange (NYSE) index, treated as a benchmark for stock indices, and with crude oil, which is a crucial commodity and could be considered as a substitute for clean energy. Furthermore, we will use the DCCA correlation coefficient to analyze the cross-correlation between the clean energy index and the other two variables analyzed. Firstly, the objective is to evaluate the degree of efficiency of these indices. Since we will use a sliding windows approach, we can also evaluate how that efficiency evolved over time. Secondly, with DCCA, we want to evaluate how these assets relate to each other. This could be important, as it could identify some kind of exposure between these markets.

The inclusion of an index representing a set of firms which produce clean energy is interesting in several ways. Firstly, individual analysis could give information about the profitability of this kind of investment. Secondly, the analysis of correlation between that and other indices could reveal the existence (or not) of connections between markets, which could also be important for existent and potential investors. Finally, and as environmental issues appear every day in the news and political speeches, information about this kind of asset could be important for actual and potential investors, with possible consequences for the attractiveness of that particular sector.

Our main results show that the clean energy index seems to be less efficient than the other indices. Moreover, over time it seems that the level of efficiency decreased. Finally, the results also show that the index is more related to the NYSE than to crude oil.

The remainder of the work is organized as follows: Section 2 presents the data and the methodology. Section 3 presents the results, and Section 4 concludes.

\section{A Literature Review on the Efficient Market Hypothesis (EMH)}

As previously stated, the analysis of financial markets is not a new issue, with [1] analyzing the evolution of French government bonds, concluding on their randomness. Over time, several other studies corroborated the possibility of asset prices being generated by random walk processes (see, for example, [8-13], among others). In general, these studies analyze the efficiency of asset prices considering the existence or not of time serial dependence, and find that the generating processes are independent and identically distributed (iid). However, some studies identify the existence of some issues called stylized facts. For example, [14] first identified that return rates are leptokurtic, while [15] concluded on the existence of volatility clustering. Other stylized facts are found and surveyed, for example, by [16,17].

Considering the existence of several analyses, [3] made a revision of both the theoretical and empirical literature devoted to the particular analysis of asset prices, identifying an efficient market as one "[ ... ]in which prices always 'fully reflect' available information [ ... ]" [3] (p. 383). Identifying three different forms of market efficiency (weak, semi-strong and strong), what is relevant for the analysis proposed in this paper is the weak form, which states that no-one can obtain abnormal profits using past information on the prices of a given asset. This hypothesis, known in the literature as the efficient market hypothesis (EMH), implies that it is not possible to predict any future pattern of prices using past information, and is the basis of several theoretical models in finance.

There is a very extensive body of analysis on the efficiency of financial markets in several different markets (countries and regions) and methodologies (linear and non-linear), which prevents a complete review of the topic. The studies by $[18,19]$ make relatively extensive reviews about the verification or not of EMH in financial markets in general. The appearance of new financial instruments, for example cryptocurrencies, means that particular financial assets have their own body of literature. For example, [20] reviews the EMH for this particular market. In this paper, we do not refer to any other study of this type, because our analysis does not concern cryptocurrencies.

The reviews of $[18,19]$ corroborate an earlier finding of $[21]$, which stated that the use of different methodologies and samples makes the analysis of EMH sensitive. Moreover, several prior studies 
adopted mainly linear approaches under the assumption that serial dependence could be analyzed with simple autocorrelation functions. However, as stated by [22], it is possible that linear methodologies do not detect some types of dependence, and in this context, the use of those methodologies is not enough to detect the possible violation of EMH in financial markets. However, at the same time, the evidence of non-linearities should also imply caution in drawing conclusions, because these non-linearities could also exist without implying rejection of EMH (see, for example, [23,24], for deeper discussions). One of the assumptions of the EMH is that market agents are rational. Recently, the view that prices could change based on non-rational individual or group reactions has made authors include other possible variables in theoretical models in finance, including complementing analysis with other social sciences (see, for example, the field of behavioral finance in [25]).

Despite contradictory results concerning verification of the EMH, it is crucial to note that even identifying that data could be generated by non-random processes, no work has been able to prove that the existence of dependence of any type (linear, non-linear, serial or other) implies market participants could gain abnormal returns in financial markets, and so rejecting the EMH.

Because of the contradictory results in the EMH literature, [26] suggested that "one new direction is to treat the EMH as an idealization that provides a useful reference point. For example, one can ask about the relative efficiency of markets with respect to each other" (p. 9992). In a certain way, the approach used in this paper follows this perspective. As we focus on the analysis of the S\&P Clean Energy Index, which as we can notice has no previous analysis, we do not present empirical work on it. For the relevant methodologies, we present evidence of the previous literature in the next section.

\section{Materials and Methods}

As previously mentioned, we want to analyze a specific stock index, which includes only shares of firms which produce clean energy. The analysis is made using Econophysics techniques, namely, the detrended fluctuation analysis (DFA) and the detrended cross-correlation analysis (DCCA). With DFA, we will analyze the serial dependence of that index, comparing it with the behavior of the NYSE index and the price of crude oil.

Created by [27] in order to analyze DNA behavior, DFA was then extended to other research areas, including finance, with prior studies such as the ones in [28-31]. The literature about the application of DFA to financial markets has increased greatly, with the studies in [32-37] being just some examples of applications of DFA or its developments, including some of the financial markets studied in this paper. The DFA is calculated as follows: considering a given time series $x_{t}$ with length $\mathrm{N}$, it starts by integrating the original time series, i.e., calculating

$$
X_{t}=\sum_{i=1}^{t}\left(x_{i}-<x>\right),
$$

with $\langle x\rangle$ being the mean value of the original time series. $X_{t}$ is then divided in time windows of length $n$, where the local trend is calculated using ordinary least squares $\left(\widetilde{X}_{t}\right)$. After this, Equation (1) is detrended, and the fluctuation function calculated as follows:

$$
F(n)=\sqrt{\frac{1}{N} \sum_{t=1}^{N}\left(X_{t}-\widetilde{X}_{t}\right)^{2}}
$$

Repeating the process for any window size of dimension $n$, it is possible to calculate the log-log regression between $F(n)$ and $n$, with the results being a power-law equal to $F(n) \propto n^{\alpha}$. The $\alpha$ exponent is a Hurst exponent with the following interpretation: if $\alpha=0.5$, the time series is described by a random walk, meaning that the given financial series could be considered as efficient; for $0.5<\alpha<1$, the time series has a persistent behavior (positive long-range dependence), while for $\alpha<0.5$, it has an anti-persistent behavior (negative long-range dependence). 
DFA will be used for the whole sample under analysis, identifying the pattern of dependence, but also with a rolling windows approach, with a size window of $n=1000$. This approach allows us to analyze the evolution of the serial dependence over time (see the work in [38-41] for examples of this application). With the various Hurst exponents obtained from the sliding windows approach, we will calculate the efficiency index (EI) defined by [42] to compare the degree of efficiency of the different assets used. The EI is given by:

$$
E I=\sqrt{\sum_{i=1}^{N}\left(\frac{M_{i}-M^{*}}{R_{i}}\right)^{2}}
$$

In Equation (3), $M_{i}$ represents each estimated DFA exponent, $M^{*}$ is equal to 0.5 (the expected value for efficiency in DFA), and $R_{i}$ is equal to 1 (the range of the DFA exponent). With the value of the EI for each time series, it is possible to compare the degree of efficiency, the most efficient variable having the lowest EI.

Besides DFA, we will use the DCCA and the respective correlation coefficient ( $\rho$ DCCA) to analyze how the S\&P Global Clean Energy Index is correlated with the NYSE and oil price. DCCA measures the long range correlation between two different variables, was introduced in the literature by [43], and has some similarities with the DFA. So, starting from the original time series $X_{t}$ and $Y_{t}$, the first step of the DCCA is also integration of the time series, as described in Equation (1). Series are equally divided into time windows of length $n$ and detrended with the same procedure, with the trend calculated by ordinary least squares. In this case, the objective is to calculate the covariance of the residuals given by

$$
f_{D C C A}^{2}(n)=\frac{1}{n-1} \sum_{k=i}^{i+n}\left(x_{k}-\tilde{x}_{k}\right)\left(y_{k}-\tilde{y}_{k}\right),
$$

used to calculate the detrended covariance given by

$$
F_{D C C A}^{2}(n)=\frac{1}{N-n} \sum_{i=1}^{N-n} f_{D C C A}^{2}
$$

After repeating for all length boxes, the DCCA exponent is obtained, given by a power law. In order to quantify the degree of the relationship between the studied pairs of time series, we use the correlation coefficient created by [44] and given by

$$
\rho_{D C C A}=\frac{F_{D C C A}^{2}}{F_{D F A\{x\}} F_{D F A\{y\}}}
$$

This is an efficient coefficient according to [45,46], and besides its use in different research areas (see the work of [47-49]), such as other Econophysics methodologies, it has applications in finance. For this purpose, see the work in [50-54], among many others. We use the procedure of [55] to test the significance of the correlation levels.

As stated, we analyze the behavior of two different stock indices (the S\&P Global Clean Energy Index and the NYSE composite index) and the WTI (West Texas Intermediate) crude oil price. The variables are transformed in return rates using the difference of logarithms on consecutive days, i.e., $r_{t}=\ln \left(p_{t}\right)-\ln \left(p_{t-1}\right)$, where $r$ refers to the return rate, $p$ the price of the asset considered, and $t$ the moment of the analysis. The sample goes from 21 November 2003 to 12 April 2019 in a total of 4015 return rates. All the data were retrieved from Datastream, with the sample starting on the date of the first available observation for the S\&P Global Clean Energy Index.

As previously mentioned, this paper is a kind of case study using a clean energy stock index, with it being difficult to compare the results with previous studies, due to the absence of previous analysis of this kind of financial variable. Previously, [56] analyzed stocks from renewable energy companies, based also on the DCCA correlation coefficient, but aiming to identify possibilities for portfolio diversification using those assets. 


\section{Results}

Firstly, we used the DFA to estimate the Hurst exponent, identified in Table 1. For the sample under analysis, the S\&P Global Clean Energy Index seems to be the most efficient, since it is closer to the 0.5 level. It is closely followed by the NYSE and then by the WTI oil price.

Table 1. Detrended fluctuation analysis (DFA) exponents for the whole sample.

\begin{tabular}{cc}
\hline Asset & DFA Exponent \\
\hline S\&P Global Clean Energy Index & $0.5124 \pm 0.0041$ \\
New York Stock Exchange (NYSE) Composite Index & $0.5178 \pm 0.0079$ \\
West Texas Intermediate (WTI) crude oil price & $0.4788 \pm 0.0093$ \\
\hline
\end{tabular}

The DFA exponents presented in Table 1 refer to the whole sample, but it would be interesting to evaluate their evolution, assessing if, over time, the variables studied have been more or less efficient. This evaluation is made using the DFA sliding windows, with the results in Figure 1.

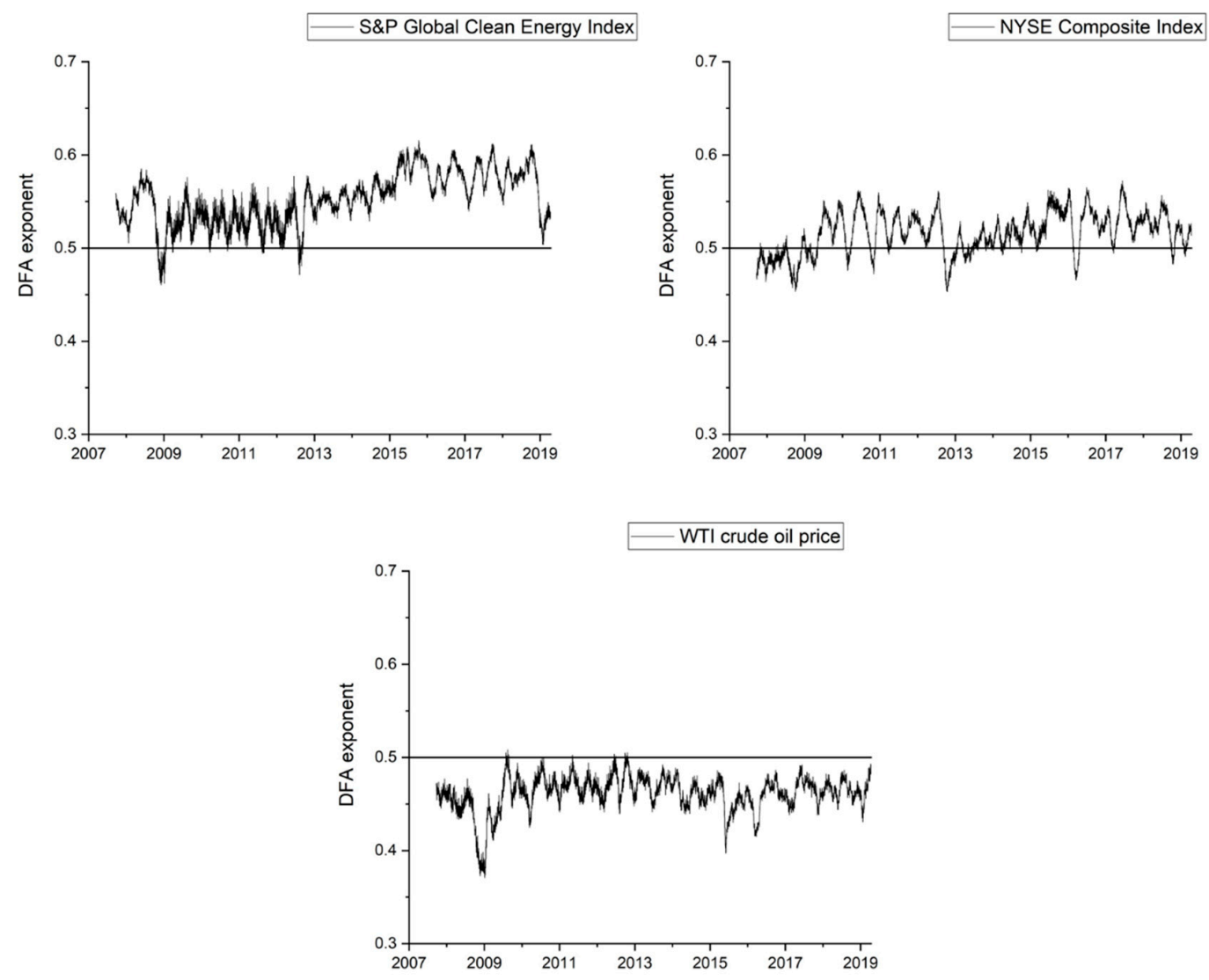

Figure 1. Evolution of the DFA exponents over time.

Figure 1 shows that the NYSE is the index with results more centered on the 0.5 level. The Clean Energy Index shows a constant persistent pattern, although with a change in the behavior of the DFA exponent: until 2013 the value was relatively stable, a little over 0.5, but since then it has increased slightly. Finally, the result for crude oil maintains an anti-persistent pattern throughout the sample. Applying the efficiency index, with the results presented in Table 2, and based on consecutive windows of sample $n=1000$, the NYSE shows the most efficient performance (having the lowest value). S\&P Global Clean Energy shows the opposite result. 
Table 2. Efficiency index of [42].

\begin{tabular}{cc}
\hline Asset & DFA Exponent \\
\hline S\&P Global Clean Energy Index & 0.0036 \\
NYSE Composite Index & 0.0008 \\
WTI crude oil price & 0.0019 \\
\hline
\end{tabular}

Besides analyzing the individual pattern of each series, we want to analyze the correlations between the different indices, with the DCCA correlation coefficient. The results presented in Figure 2 show that all the coefficients are statistically significant, since they are outside the upper limit. However, the highest correlation is between S\&P Clean Energy and the NYSE, followed by the correlation between NYSE and the crude oil price, and finally the correlation between the Clean Energy Index and the crude oil price. The results show that Clean Energy is less exposed to crude oil, which is expected, because they are substitute sources of energy. Nevertheless, it is closely related to the NYSE Index.

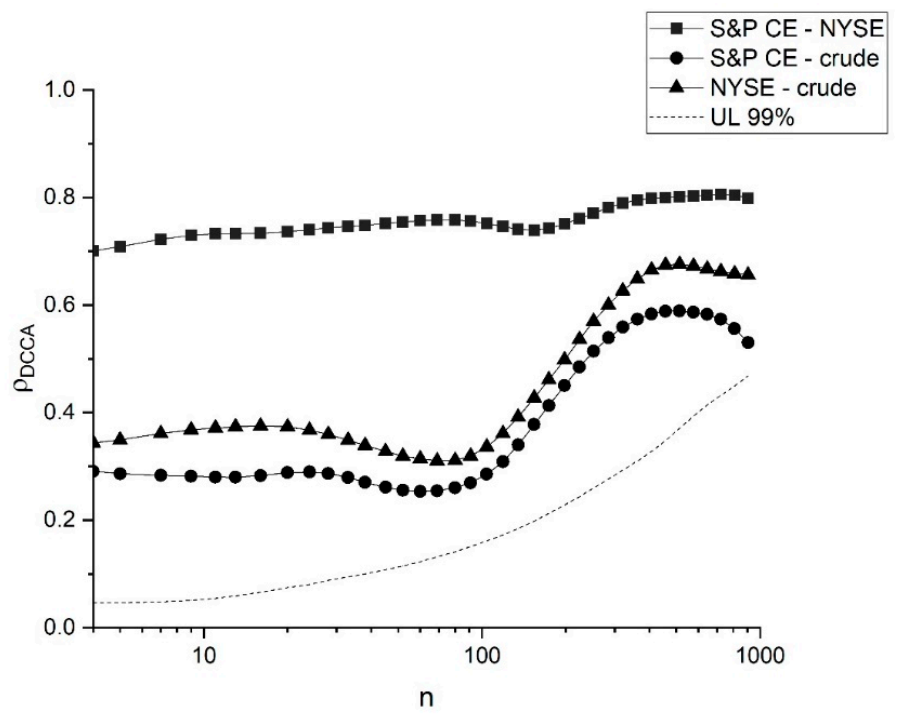

Figure 2. Detrended cross-correlation analysis (DCCA) correlation coefficients between pairs of series.

\section{Discussion and Concluding Remarks}

In this work, we apply Econophysics techniques to study the behavior of three different financial time series: the S\&P Clean Energy Index, the NYSE composite index, and crude oil price. Firstly, we apply detrended fluctuation analysis, which allows two different analyses: how each of those assets behaves in terms of serial dependence, and how that dependence evolves over time (since we apply a sliding windows approach). Then, the correlation coefficients from the detrended cross-correlation analysis are calculated to compare how those assets correlate with each other.

The results of this work demonstrate firstly that the S\&P Clean Energy Index seems to be less efficient than the general NYSE composite index and also than the crude oil price. This conclusion is drawn considering the efficiency index and evolution of the DFA exponents, which show persistent levels during almost all the sample, without decreasing over time. These particular results are very interesting and could be used by investors. As the possible inefficiency could give some information about the predictability of the assets' behavior, it could make it more interesting for investors to focus on this particular market.

When assessing the correlation between the financial assets analyzed, the results show that the clean energy index is strongly related to the NYSE but is less connected with oil than the NYSE index. These results may not be surprising, not only because they show the relationship with the general index, but also due to showing some segmentation from the results of crude oil. Moreover, in the long 
run (higher scales), the correlation is almost non-significant. This reduced connection shows that the factors influencing both sectors are different.

Nowadays, environmental activity is recognized not only because of its crucial role in the demand for sustainable development, but also as a possibly profitable activity. So, the closer connection with the NYSE could be considered natural. Regarding the connection with crude oil, although significant, the results are lower. This is in line with [56], who conclude that investing in portfolio assets from firms producing energy from alternative sources could be a good diversification strategy.

Globally, despite the interesting results, there is still room to continue to study the same kind of variables in the future. On the one hand, one possible explanation for the reduced efficiency levels when compared with the NYSE or with oil could be the fact that some components of the clean energy index are new firms and/or recently listed. The assets incorporated in the index could have reduced liquidity levels, when compared with more mature markets. Features like liquidity or firm size could be relevant in firms' individual results (see, for example, [34,57]) and could be included in future research. On the other hand, with the constant concerns about the environment and continuous evolution of the market raising interest in this kind of investment, it is expected that efficiency levels could improve in the near future. There is confirmation that the development of social responsibility in firms could have a positive impact on stock markets' financial performance (see, for example, [58]). This linkage between corporate social responsibility and financial performance could also be studied in the future. This cannot be analyzed directly in this paper, since we use index data rather than individual data. This is one limitation of the study, which could be remedied in future research.

In conclusion, the possible attractiveness of the clean energy market could mean more money being directed to that sector, with firm managers having more possibilities for investing in strategies to make energy production more efficient. In the long term, this could produce major benefits for the environment and society as a whole. This is relevant for potential investors but could also be important for policy-makers, who could use this kind of information to promote the necessary policies to reach sustainable development objectives.

Finally, and based on the results, we would like to end with a clarification. Although we find that some of the indices/assets studied are more linked with a possible inefficient pattern, because the evidence of dependence is higher, this is not proof that those dependences imply some capacity of predictability in financial assets. In line with [59], we should exercise caution when analyzing the results, so when talking about efficiency, we intend to do so qualitatively. Nevertheless, it is still important to study financial market dependence, because these issues remain important for actual and potential investors, this being also a task for future research.

Author Contributions: Conceptualization, P.F. and L.C.L.; Data curation, P.F. and L.C.L.; Formal analysis, P.F. and L.C.L.; Methodology, P.F. and L.C.L.; Writing-original draft, P.F. and L.C.L.; Writing-review and editing, P.F. and L.C.L. All authors have read and agreed to the published version of the manuscript.

Funding: Paulo Ferreira is pleased to acknowledge financial support from Fundação para a Ciência e a Tecnologia (grant UID/ECO/04007/2019).

Conflicts of Interest: The authors declare no conflict of interest.

\section{References}

1. Bachelier, L. Théorie de la spéculation. Ann. Sci. Éc. Norm. Supér. 1900, 17, 21-86. [CrossRef]

2. Fama, E. Mandelbrot and the Stable Paretian Hypothesis. J. Bus. 1963, 36, 420-429. [CrossRef]

3. Fama, E. Efficient capital markets: A review of theory and empirical work. J. Financ. 1970, 25, 383-417. [CrossRef]

4. Gallegati, M. Beyond econophysics (not to mention mainstream economics). Eur. Phys. J. Spec. Top. 2016, 225, 3179-3185. [CrossRef]

5. Jovanovic, F.; Schinckus, C. Breaking down the barriers between econophysics and financial economics. Int. Rev. Financ. Anal. 2016, 47, 256-266. [CrossRef]

6. Schinckus, C. 1996-2016: Two decades of econophysics: Between methodological diversification and conceptual coherence. Eur. Phys. J. Spec. Top. 2016, 225, 3299-3311. [CrossRef] 
7. Pereira, E.; Silva, M.; Pereira, H. Econophysics: Past and present. Physica A 2017, 473, 251-261. [CrossRef]

8. Osborne, M. Brownian motion in the stock market. Oper. Res. 1959, 7, 145-173. [CrossRef]

9. Osborne, M. Periodic structure in the Brownian motion of stock prices. Oper. Res. 1962, 10, 345-379. [CrossRef]

10. Alexander, S. Price movements in speculative markets: Trends or random walks. Ind. Manag. Rev. 1961, 2, 7-26.

11. Cootner, P. Stock prices: Random vs. systematic changes. Ind. Manag. Rev. 1962, 3, $24-45$.

12. Samuelson, P. Proof that properly anticipated prices fluctuate randomly. Ind. Manag. Rev. 1965, 6, 41-49.

13. Granger, C.; Morgenstern, O. Spectral analysis of New York stock market prices. Kyklos 1963, 16, 1-27. [CrossRef]

14. Mandelbrot, B. The variation of certain speculative prices. J. Bus. 1963, 36, 394-419. [CrossRef]

15. Mandelbrot, B.; Wallis, J. Some long-run properties of geophysical records. Water Resour. Res. 1969, 5, 321-340. [CrossRef]

16. Cont, R. Empirical properties of asset returns: Stylized facts and statistical issues. Quant. Financ. 2001, 1, 223-236. [CrossRef]

17. Parisi, D.; Sornette, D.; Helbing, D. Financial price dynamics and pedestrian counterflows: A comparison of statistical stylized facts. Phys. Rev. E 2013, 87, 012804. [CrossRef]

18. Yen, G.; Lee, C. Efficient market hypothesis (EMH): Past, present and future. Rev. Pac. Basin Fin. Mark. Policies. 2008, 11, 305-329. [CrossRef]

19. Titan, A. The Efficient Market Hypothesis: Review of Specialized Literature and Empirical Research. Proc. Econ. Financ. 2015, 32, 442-449. [CrossRef]

20. Kyriazis, N. A Survey on Efficiency and Profitable Trading Opportunities in Cryptocurrency Markets. J. Risk. Fin. Manag. 2019, 12, 67. [CrossRef]

21. Fama, E. Market efficiency, long-term returns, and behavioral finance. J. Fin. Econ. 1998, 49, 283-306. [CrossRef]

22. Granger, C.; Maasoumi, E.; Racine, J. A dependence metric for possibly nonlinear processes. J. Time Ser. Anal. 2004, 25, 649-669. [CrossRef]

23. Andreou, E.; Pittis, N.; Spanos, A. On modelling speculative prices: The empirical literature. J. Econ. Surv. 2001, 15, 187-220. [CrossRef]

24. McCauley, J.; Bassler, K.; Gunaratne, G. Martingales, detrending data, and the efficient market hypothesis. Physica A 2008, 387, 202-216. [CrossRef]

25. Shiller, R. From efficient markets theory to behavioral finance. J. Econ. Perspect. 2003, 17, 83-104. [CrossRef]

26. Farmer, D.; Lo, A. Frontiers of finance: Evolution and efficient markets. Proc. Natl. Acad. Sci. USA 1999, 96, 9991-9992. [CrossRef]

27. Peng, C.; Buldyrev, S.; Havlin, S.; Simons, M.; Stanley, E.; Goldberger, A. Mosaic organization of DNA nucleotides. Phys. Rev. E 1994, 49, 1685-1689. [CrossRef]

28. Vandewalle, N.; Ausloos, M. Coherent and random sequences in financial fluctuations. Physica A 1997, 246, 454-459. [CrossRef]

29. Liu, Y.; Cizeau, P.; Meyer, M.; Peng, C.; Stanley, H. Correlations in economic time series. Physica A 1997, 245, 437-440. [CrossRef]

30. Ausloos, M.; Vandewalle, N.; Boveroux, P.; Minguet, A.; Ivanova, K. Applications of statistical physics to economic and financial topics. Physica A 1999, 274, 229-240. [CrossRef]

31. Ausloos, M. Statistical physics in foreign exchange currency and stock markets. Physica A 2000, 285, 48-65. [CrossRef]

32. Cao, G.; Zhang, M. Extreme values in the Chinese and American stock markets based on detrended fluctuation analysis. Physica A 2015, 436, 25-35. [CrossRef]

33. Anagnostidis, P.; Varsakelis, C.; Emmanouilides, C. Has the 2008 financial crisis affected stock market efficiency? The case of Eurozone. Physica A 2016, 447, 116-128. [CrossRef]

34. Ferreira, P.; Loures, L.; Nunes, J.; Dionísio, A. The behaviour of share returns of football clubs: An econophysics approach. Physica A 2017, 472, 136-144. [CrossRef]

35. Alvarez-Ramirez, J.; Alvarez, J.; Rodriguez, E. Short-term predictability of crude oil markets: A detrended fluctuation analysis approach. Energy Econ. 2008, 30, 2645-2656. [CrossRef]

36. Wang, Y.; Wei, Y.; Wu, C. Detrended fluctuation analysis on spot and futures markets of West Texas Intermediate crude oil. Physica A 2011, 390, 864-875. [CrossRef] 
37. Gu, R.; Chen, H.; Wang, Y. Multifractal analysis on international crude oil markets based on the multifractal detrended fluctuation analysis. Physica A 2010, 389, 2805-2815. [CrossRef]

38. Cajueiro, D.; Tabak, B. The Hurst exponent over time: Testing the assertion that emerging markets are becoming more efficient. Physica A 2004, 336, 521-537. [CrossRef]

39. Cajueiro, D.; Tabak, B. Evidence of long range dependence in Asian equity markets: The role of liquidity and market restrictions. Physica A 2004, 342, 656-664. [CrossRef]

40. Cajueiro, D.; Tabak, B. Testing for predictability in equity returns for European transition markets. Econ. Syst. 2006, 30, 56-78. [CrossRef]

41. Cajueiro, D.; Tabak, B. Testing for time-varying long-range dependence in real estate equity returns. Chaos Soliton. Fract. 2008, 38, 293-307. [CrossRef]

42. Kristoufek, L.; Vosvrda, M. Measuring capital market efficiency: Global and local correlations structure. Physica A 2013, 392, 184-193. [CrossRef]

43. Podobnik, B.; Stanley, H. Detrended Cross-Correlation Analysis: A new method for analyzing two nonstationary time series. Phys. Rev. Lett. 2008, 100, 084102. [CrossRef] [PubMed]

44. Zebende, G. DCCA cross-correlation coefficient: Quantifying level of cross-correlation. Physica A 2011, 390, 614-618. [CrossRef]

45. Kristoufek, L. Measuring cross-correlation between non-stationary series with DCCA coefficient. Physica A 2014, 402, 291-298. [CrossRef]

46. Zhao, X.; Shang, P.; Huang, J. Several fundamental properties of DCCA cross-correlation coefficient. Fractals 2017, 25, 1750017. [CrossRef]

47. Filho, A.; Silva, M.; Zebende, G. Autocorrelation and cross-correlation in time series of homicide and attempted homicide. Physica A 2014, 400, 12-19. [CrossRef]

48. Zebende, G.; Fernandez, B.; Pereira, M. Analysis of the variability in the sdB star KIC 10670103: DFA approach. Mon. Not. R. Astron. Soc. 2017, 464, 2611-2642. [CrossRef]

49. Zebende, G.; Brito, A.; Filho, A.; Castro, A. $\rho$ DCCA applied between air temperature and relative humidity: An hour/hour view. Physica A 2017, 494, 17-26. [CrossRef]

50. Reboredo, J.; Rivera-Castro, M.; Zebende, G. Oil and US dollar exchange rate dependence: A detrended cross-correlation approach. Energ. Econ. 2014, 42, 132-139. [CrossRef]

51. Hussain, M.; Zebende, G.; Bashir, U.; Donghong, D. Oil price and exchange rate co-movements in Asian countries: Detrended cross-correlation approach. Physica A 2017, 465, 338-346. [CrossRef]

52. Ferreira, P.; Pereira, É.; Silva, M.; Pereira, H. Detrended correlation coefficients between oil and stock markets: The effect of the 2008 crisis. Physica A 2019, 517, 86-96. [CrossRef]

53. Wang, G.; Xie, C.; Chen, S.; Yang, J.; Yang, M. Random matrix theory analysis of cross-correlations in the US stock market: Evidence from Pearson's correlation coefficient and detrended cross-correlation coefficient. Physica A 2013, 392, 3715-3730. [CrossRef]

54. Ferreira, P.; Dionísio, A. How long is the memory of the US stock market? Physica A 2017, 451, 502-506. [CrossRef]

55. Podobnik, B.; Jiang, Z.; Zhou, W.; Stanley, H. Statistical tests for power-law cross-correlated processes. Phys. Rev. E 2011, 84, 066118. [CrossRef]

56. Ferreira, P.; Loures, L.; Nunes, J.; Brito, P. Are renewable energy stocks a possibility to diversify portfolios considering an environmentally friendly approach? The view of DCCA correlation coefficient. Physica A 2018, 512, 675-681. [CrossRef]

57. Dang, C.; Li, Z.; Yang, C. Measuring firm size in empirical corporate finance. J. Bank. Financ. 2018, 86, 159-176. [CrossRef]

58. Li, Z.; Minor, D.; Wang, J.; Yu, C. A learning curve of the market: Chasing alpha of socially responsible firms. J. Econ. Dyn. Control 2019, 109, 103772. [CrossRef]

59. Ausloos, M.; Jovanovic, F.; Schinckus, C. On the "usual" misunderstandings between econophysics and finance: Some clarifications on modelling approaches and efficient market hypothesis. Int. Rev. Financ. Anal. 2016, 47, 7-14. [CrossRef]

(C) 2020 by the authors. Licensee MDPI, Basel, Switzerland. This article is an open access article distributed under the terms and conditions of the Creative Commons Attribution (CC BY) license (http://creativecommons.org/licenses/by/4.0/). 